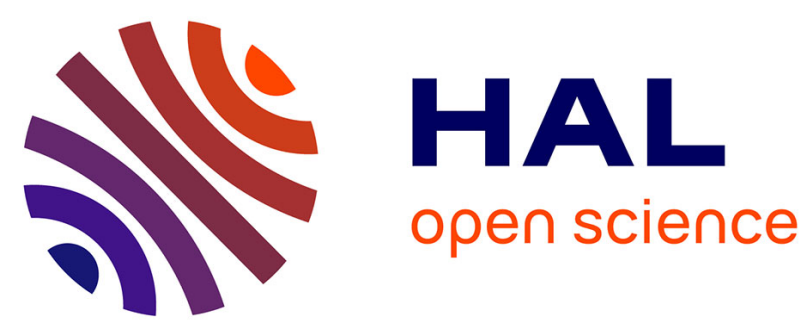

\title{
Effect of heat treatment on AgI-rich chalcogenide glasses with enhanced ionic conductivity
}

Xinyu Huang, Qing Jiao, Changgui Lin, Yeting Zhang, Zhen Yang, Tiefeng Xu, Xianghua Zhang, Hongli Ma, Xueyun Liu, Shixun Dai

\section{- To cite this version:}

Xinyu Huang, Qing Jiao, Changgui Lin, Yeting Zhang, Zhen Yang, et al.. Effect of heat treatment on AgI-rich chalcogenide glasses with enhanced ionic conductivity. Journal of the American Ceramic Society, 2019, 102 (3), pp.1309-1315. 10.1111/jace.16010 . hal-01952396

HAL Id: hal-01952396 https://hal-univ-rennes1.archives-ouvertes.fr/hal-01952396

Submitted on 12 Dec 2018

HAL is a multi-disciplinary open access archive for the deposit and dissemination of scientific research documents, whether they are published or not. The documents may come from teaching and research institutions in France or abroad, or from public or private research centers.
L'archive ouverte pluridisciplinaire HAL, est destinée au dépôt et à la diffusion de documents scientifiques de niveau recherche, publiés ou non, émanant des établissements d'enseignement et de recherche français ou étrangers, des laboratoires publics ou privés. 
MR. XINYU HUANG (Orcid ID : 0000-0001-7112-8106)

DR QING JIAO (Orcid ID : 0000-0003-1482-6981)

DR CHANGGUI LIN (Orcid ID : 0000-0002-0574-6296)

Article type : Article

\section{Effect of heat treatment on AgI-rich chalcogenide glasses with enhanced ionic conductivity}

Corresponding author mail id :- 1175032149@qq.com

\section{Xinyu Huang ${ }^{1}$ | Qing Jiao ${ }^{1}{ }^{*}$ Changgui Lin ${ }^{1}$ Yeting Zhang $^{1} \mid$ Zhen Yang $^{1} \mid$ Tiefeng Xu $^{1} \mid$ Xianghua Zhang ${ }^{2} \mid$ Hongli Ma $^{2} \mid$ Xueyun Liu ${ }^{1} \mid$ Shixun Dai ${ }^{1}$}

${ }^{1}$ Key Laboratory of Photoelectric Detection Materials and Devices of Zhejiang Province, Ningbo University, 315211, Ningbo, China

${ }^{2}$ Laboratory of Glasses and Ceramics, Institute of Chemical Science UMR CNRS 6226, University of Rennes 1, 35042, Rennes, France
Abstract
The glass ceramics of AgI-based electroconductive chalcogenide system was realized by using an appropriate heat treatment at a fairly high temperature $\left(T_{g}+40{ }^{\circ} \mathrm{C}\right)$ and different times ranging from $4 \mathrm{~h}$ to $20 \mathrm{~h}$. The crystallization behavior and electroconductive properties of the heat-treated samples were studied in detail. Transmission study was performed, and the results show that the cut-off edge of the short wavelength is red-shifted at prolonged This article has been accepted for publication and undergone full peer review but has not been through the copyediting, typesetting, pagination and proofreading process, which may lead to differences between this version and the Version of Record. Please cite this article as doi: $10.1111 /$ jace. 16010
This article is protected by copyright. All rights reserved. 
annealing time but remains an excellent transmittance in the mid-infrared (IR) region. XRD and SEM results indicated that the precipitated crystalline phases are mainly $\beta$ - $/ \gamma$-AgI. Moreover, a small amount of $\alpha-\mathrm{AgI}$, which is rarely existed at room temperature, is precipitated in the AgI-rich chalcogenide glass-ceramics. The ionic conductivity of all glass-ceramics was enhanced by heat treatment in contrast to that of base glass. Raman analysis exhibited the structure variation of the glass sample after heat treatments. This study provided an observation of crystallization in chalcogenide glass containing large amounts of $\mathrm{AgI}$ and be of good guidance to fabricate novel AgI-based chalcogenide glass-ceramics that can be candidates in infrared optics and solid electrolyte applications.

\section{1 | INTRODUCTION}

Alkali-doped chalcogenide glasses have attracted much attention because of their good glass-forming ability, low phonon energy, extended infrared transparency, ${ }^{1,2}$, and because of their potential applications in optical fibers, chemical sensors, and solid-state electrolytes ${ }^{3-5}$. However, their application scope is often limited owing to their weak mechanical properties and poor thermal stability. Crystallization process on glasses after heat treatment is one of the approaches enhancing their stability for satisfying applications. This approach improves the thermo-mechanical properties, particularly thermal expansion, thermal shock sensitivity, and resistance to crack propagation of chalcogenide glasses ${ }^{6}$. Notably, microcrystals of AgI contained chalcogenide glass-ceramic have become a focus research because of their potential application in solid-state batteries ${ }^{7-9}$, in which $\mathrm{Ag}^{+}$ions exhibit high ionic conductivity exceeding $10^{-3} \mathrm{~S} / \mathrm{cm}$ at room temperature. Superionic conductor $\alpha-\mathrm{AgI}$ has a This article is protected by copyright. All rights reserved. 
high ionic conductivity of $1 \mathrm{~S} / \mathrm{cm}$ when it is thermodynamically stable above $147^{\circ} \mathrm{C}$. Phase transformation from $\alpha$-AgI to a low-temperature phase, $\beta$ - $/ \gamma$-AgI, usually occurs at $147{ }^{\circ} \mathrm{C}$, which is still difficult to inhibit this transformation and stabilizing the superionic conductor $\alpha-A g I$ in glasses and ceramics. High-temperature phase $\alpha-A g I$ can be stabilized at room temperature, although only in oxide glasses ${ }^{10}$. For example, Tatsumisago successfully stabilized $\alpha-\mathrm{AgI}$ in $\mathrm{AgI}-\mathrm{Ag}_{2} \mathrm{O}-\mathrm{B}_{2} \mathrm{O}_{3}$ glass-ceramic at room temperature through a twin-roller rapid quenching technique ${ }^{11,12}$. Meanwhile, conductivity of AgI-based phosphate glasses can be enhanced after appropriate crystallization process $^{13}$. Compared with glassy oxides, chalcogenide glassy electrolytes are particularly promising for the high ionic conductivity and superior ductility allowing for room temperature processing, which makes them more suitable for use in all-solid-state baterries ${ }^{14}$. Therefore, exploring novel chalcogenide glass solid electrolytes with optimum combination of high room-temperature conductivity $\left(10^{-4}\right.$ $\mathrm{S} / \mathrm{cm}$ ) and chemical stability has become a focus of substantial research.

$\mathrm{Ga}-\mathrm{Sb}-\mathrm{S}$ glass is a recent novel Ge-free system that has a broader transmission range and lower cost than Ge-based chalcogenide glasses. In our previous work ${ }^{15}$, we successfully introduced a large amount of $\mathrm{AgI}$ in a Ga-Sb-S glass matrix, which subsequently exhibited good glass-forming ability, transparency, and heat stability. To fabricate chalcogenide glass-ceramics used in solid batteries, we investigated glass composition of $40\left(0.8 \mathrm{Sb}_{2} \mathrm{~S}_{3}-0.2 \mathrm{Ga}_{2} \mathrm{~S}_{3}\right)-60 \mathrm{AgI}$ containing large amounts of $\mathrm{AgI}$. The effect of heat treatment on crystallization behavior is important to the electroconductive properties of the chalcogenide glasses, especially to $\mathrm{AgI}$ phase transformation associated with high conductivity. Therefore, elaborating the crystalline mechanism and phase transformation of This article is protected by copyright. All rights reserved. 
AgI-based chalcogenide glasses for opt-electric applications is necessary, especially for the establishment of high-conductivity AgI phase containing chalcogenide solid electrolyte materials.

\section{2 | EXPERIMENTAL PROCEDURES}

Bulk glass $(20 \mathrm{~g})$ with a composition of $40\left(0.8 \mathrm{Sb}_{2} \mathrm{~S}_{3}-0.2 \mathrm{Ga}_{2} \mathrm{~S}_{3}\right)-60 \mathrm{AgI}$ was prepared by the conventional melt-quenching technique. The weighed highly pure gallium $(6 \mathrm{~N})$, antimony $(5 \mathrm{~N})$, sulfur $(5 \mathrm{~N})$, and silver iodide $(4 \mathrm{~N})$ were weighted and placed into separate cleaned quartz glass ampoules, which were then sealed under a vacuum of $10^{-3} \mathrm{~Pa}$. A sealed ampoule with an inner diameter of $10 \mathrm{~mm}$ was placed in a rocking furnace. The raw materials were heated from $25{ }^{\circ} \mathrm{C}$ to $850{ }^{\circ} \mathrm{C}$ at a $2{ }^{\circ} \mathrm{C} / \mathrm{min}$ heating rate, maintained at this temperature for 12 $\mathrm{h}$ in the rocking furnace, further equilibrated at $700{ }^{\circ} \mathrm{C}$, and finally quenched in cold water. To remove the inner constraints during rapid quenching, we swiftly transferred the alloys to a preheated furnace and annealed them at $T_{g}$ of $-30{ }^{\circ} \mathrm{C}$ for $5 \mathrm{~h}$. The bulk glasses were obtained by removing them from the ampoules, and the glass rods were finally cut and polished into disks of $10 \mathrm{~mm}$ in diameter and $2 \mathrm{~mm}$ in thickness. Glass-ceramics were obtained in the same annealing furnace after heat treatments at a fixed temperature of $40{ }^{\circ} \mathrm{C}$ above $\mathrm{T}_{\mathrm{g}}$ for different durations (4h, $8 \mathrm{~h}, 12 \mathrm{~h}$ and $20 \mathrm{~h})$ in air condition. Glass characteristic temperatures, including glass transition temperature $\left(T_{g}\right)$ and onset temperature of crystallization $\left(T_{x}\right)$, were identified by heating $10 \mathrm{mg}$ of the samples in a hermetic aluminum pan at a $10{ }^{\circ} \mathrm{C} / \mathrm{min}$ rate under $\mathrm{N}_{2}$ atmosphere in a differential scanning calorimeter (TA Instruments Q2000, New Castle, DE). Then, we heat-treated the obtained disks at $2^{\circ} \mathrm{C} / \mathrm{min}$ to a designed temperature and held for different durations to obtain glass ceramics.

This article is protected by copyright. All rights reserved. 
Optical transmission spectra ranging from $0.25 \mu \mathrm{m}$ to $16 \mu \mathrm{m}$ were recorded by using a PerkinElmer Lambda 950 spectrophotometer and a Nicolet 380 FT-IR spectrometer. Elemental analysis and crystalline morphology in the glass-ceramic was observed with a scanning electron microscope (Hitachi S-4800, Japan) with an accelerating voltage of $15 \mathrm{kV}$. Observation was performed on freshly glass surface. The crystalline phase precipitated in heat treatment samples were identified by using X-Ray diffraction (XRD) and compared with JCPDF cards. Room temperature XRD was performed with a Bruker D2 diffractometer (Bruker D2 Phaser, $\lambda=0.15406 \mathrm{~nm}, 30 \mathrm{kV}, 10 \mathrm{~mA}, \mathrm{CuK \alpha}$ ) in a reflection mode at room temperature in a $2 \theta$ range of $10^{\circ}-70^{\circ}$. Raman spectra were obtained at room temperature by using the back-scattering configuration of a laser confocal Raman spectrometer (type: Renishaw inVia, Gloucestershine, UK) with an excitation wavelength at $785 \mathrm{~nm}$. The resolution of the Raman spectrum was $1 \mathrm{~cm}^{-1}$. For electrical measurements, gold electrodes with a diameter of $8 \mathrm{~mm}$ were sputtered on the parallel surfaces of the as-prepared samples. Using a frequency response analyzer (CHI 660e), we measured electrical conductivity through a complex impedance technique over a wide range of frequencies from $1 \mathrm{~Hz}$ to 1 MHz. Ac impedance was measured at room temperature and all performed measurements were found to be well reproducible. In addition, several precautions to prepare the uniform and homogenous samples during preparation were taken like that all glass samples were stuck in the same mold polished to keep the same in thickness and smoothness

This article is protected by copyright. All rights reserved. 


\section{3 | RESULTS AND DISCUSSION}

DSC trace of the as-quenched precursor glass with the labeled characteristic temperatures $\left(T_{g}\right.$, $\left.T_{x 1}, T_{x 2}\right)$ is presented in Figure 1. The $\Delta T\left(\Delta T=T_{x 1}-T_{g}\right)$ value, which indicates the devitrification tendency of a glass when heated above $T_{g}$, is determined to be $155^{\circ} \mathrm{C}$. The $\Delta T$ value of $\sim 142{ }^{\circ} \mathrm{C}$ means the mechanical and thermal stability of the samples during heating. The small exothermic peak locating at $297{ }^{\circ} \mathrm{C}$ is originated from the crystallization in the glass matrix. According to previous research ${ }^{6,16,17}$, a suitable heat treatment temperature usually ranges from $10{ }^{\circ} \mathrm{C}$ to $30{ }^{\circ} \mathrm{C}$ above $T_{g}$. In this work, considering the high $\Delta T$, we selected a high $T_{H T}\left(T_{g}+40{ }^{\circ} \mathrm{C}\right)$ to render the crystallization process controllable. We placed the base glasses in a ventilated furnace at $195{ }^{\circ} \mathrm{C}$ from $4 \mathrm{~h}$ to $20 \mathrm{~h}$ to obtain crystallized samples. The Vis-NIR transmission spectra of the glass samples are presented in Figure 2. The absorption bands at $2.9 \mu \mathrm{m}, 4.1 \mu \mathrm{m}, 6.3 \mu \mathrm{m}$, and $9.6 \mu \mathrm{m}$ can be attributed to $-\mathrm{OH},-\mathrm{SH}$, $\mathrm{H}_{2} \mathrm{O}$, and $\mathrm{Sb}-\mathrm{O}$, respectively. These IR impurity absorption peaks are due to the hygroscopic property of AgI. The optical transmission of glass-ceramics usually decrease as the size of precipitated crystals become close to the incident wavelength owing to the increase of scattering loss in the UV-NIR light region ${ }^{18}$. Thus, heat treatment must be performed in such manner that the crystals precipitated from the glass matrix are small enough for good optical transmittance in the required IR region. As shown in Figure 2a, the Vis-NIR transmittance of the samples is extremely sensitive to the precipitation of crystals. The sample heat-treated for 4, 8, and $12 \mathrm{~h}$ showed decline in transmission from $650 \mathrm{~nm}$ to $2500 \mathrm{~nm}$ but had good transparency levels in the mid-IR region. The cut-off edge of short wavelength red-shifted at prolonged heat-treatment time $(4 \mathrm{~h}$ to $20 \mathrm{~h}$ ), indicating the nucleation and growth of the This article is protected by copyright. All rights reserved. 
crystals in the glassy matrix. Moreover, a large drop in maximum transmittance was observed when the heat-treatment duration was prolonged to $20 \mathrm{~h}$. The possible reason is the growth and agglomeration of the precipitated crystallites. The agglomeration of the precipitated crystals is shown in the scanning electron microscopy (SEM) micrographs.

To evaluate the size and distribution of the crystalline particles, we performed SEM analysis on the fresh surface of the base glass and glass-ceramic specimens crystallized at $195^{\circ} \mathrm{C}$ at various time. Figure 3(a) shows the initial stage of the base glass, while Figure 3(b) and 3(c) show the well-defined growing crystals. The grains of specimens crystallized at $195{ }^{\circ} \mathrm{C}$ for $4 \mathrm{~h}$ were small $(\sim 200 \mathrm{~nm})$. As shown in the distribution of the precipitated crystallites in the image, the grains and grain boundaries became distinct. After the heat treatment time increased to $8 \mathrm{~h}$, the sizes of most of the crystallized grains increased to 500 $\mathrm{nm}$, as shown in Figure 3(c). As the crystallization time reached $20 \mathrm{~h}$, a wide distribution of grain shape and size $(2 \mu \mathrm{m})$ was observed (Figure 3(d)). An increase in grain size at crystallization time of 4-20 h was more evident, and grain size distribution remained fairly uniform, although some irregular and large grains were noted in the micrograph (Figure 3(d)). At prolonged heat treatment time, the size of the crystals increased further, and the Mie diffusion shifted the cut-off edge to the short wavelength. This shift was in good agreement with Vis-IR spectra. Notably, it should be clear that the crystalline is located on the bulk surface about $10 \mu \mathrm{m}$ according to our further cross-section SEM measurement. As can be seen the EDS results in Table 1, the weight percentage of Ag increased from $18.87 \%$ to $27 \%$, while the base glass and I atomic weight percentage increased from $21.19 \%$ to $28.45 \%$ in the marked region. Meanwhile, $\mathrm{Ga}, \mathrm{Sb}$, and $\mathrm{S}$ contents decreased, suggesting that the precipitated This article is protected by copyright. All rights reserved. 
crystalline phase is assigned to the AgI phase. Although $\mathrm{O}$ was found in the base glass and glass-ceramic, however, the oxides ratio is rarely small and the influence of oxides in this research will be neglected in the ionic conductivity study.

As depicted in Figure 4, the XRD patterns of the samples heat-treated for different durations were collected by detecting the base glass and glass-ceramics. First, the XRD of the base glass exhibited a broad hump without any detectable sharp peak in the same manner as amorphous materials. When the heat treatment time was increased from $4 \mathrm{~h}$ to $20 \mathrm{~h}$, three different crystal phases were precipitated in these samples. Several peaks appeared at the following locations: $22.4^{\circ}, 23.8^{\circ}, 24.7^{\circ}, 39.2^{\circ}$, and $46.3^{\circ}$, which agree well with that of standard $\alpha$-AgI (JCPDF card of no. 70-1022), $\beta$-AgI ((JCPDF card of no. 78-1655) and $\gamma$-AgI (JCPDF card of no. 9-399). The precipitated crystals were mainly $\gamma$-AgI and $\beta$-AgI phases, and a small amount of $\alpha$-AgI phase was observed in the AgI-riched chalcogenide glass-ceramics. As the heat treatment time increased to $20 \mathrm{~h}$, the diffraction peak became significant, and the amplitude of the peak assigned to $\alpha-\mathrm{AgI}$ increased, suggesting increase in the size and magnitude of the crystallites. The results indicated that the number of $\alpha$-Agl nuclei was saturated in the glass matrix during the quenching process and most of the precipitation crystals were still the low temperature phase of AgI. For the high conductive chalcogenide glass and ceramics, large superior conductors of $\alpha$-AgI phase is a pursuit in research hoping effective solid electronic materials.

We detected the Raman spectra of the samples with laser confocal Raman spectrometer to trace the structural evolution of crystallization. As shown in Figure 5, the Raman spectra were dominated by the bands between 50 and $400 \mathrm{~cm}^{-1}$, which are composed of several overlapped This article is protected by copyright. All rights reserved. 
bands. The Raman bands and their corresponding assignments for base glass and glass-ceramic are summarized in Table 2. Two main changes were observed when heat treatment time was increased. The first was the increased amplitude of $107 \mathrm{~cm}^{-1}$ and decreased amplitude of the shoulder peak at $138 \mathrm{~cm}^{-1}$. According to many research ${ }^{7,19,22}$, the shoulder peak around $107 \mathrm{~cm}^{-1}$ is corresponding to [SbSI] and $\beta$-AgI, and that at $138 \mathrm{~cm}^{-1}$ corresponds to $\left[\mathrm{SbI}_{3}\right]$ unit. The crystallization of $\mathrm{AgI}$ decreased $\mathrm{I}^{-}$concentration in the glass matrix and converted the $\left[\mathrm{SbI}_{3}\right]$ structural units to $[\mathrm{SbSI}]$. The second change was that the Raman band around $275 \mathrm{~cm}^{-1}$ shifted to $265 \mathrm{~cm}^{-1}$. Considering the previous studies on chalcogenide glass containing $\mathrm{AgI}$ and the vibration theory ${ }^{15}$, we surmised that the peak at $275 \mathrm{~cm}^{-1}$ is caused by the formation of the $\left[\mathrm{SbS}_{3-\mathrm{x}} \mathrm{I}_{\mathrm{x}}\right]$ mixed structure ${ }^{23}$. Owing to the precipitation of $\mathrm{AgI},\left[\mathrm{SbS}_{3-\mathrm{x}} \mathrm{I}_{\mathrm{x}}\right]$ and $\left[\mathrm{GaS}_{4-\mathrm{x}} \mathrm{I}_{\mathrm{x}}\right]$ units decreased in amount and decomposed to the $[\mathrm{SbSI}],\left[\mathrm{SbS}_{3}\right]$, and $\left[\mathrm{GaS}_{3}-\mathrm{S}_{3} \mathrm{Ga}\right]$ units to compensate the loss of $\mathrm{I}^{-}$in the network structure. With referenced to the Raman vibrations of $\mathrm{SbSI}$ and $\mathrm{SbI}_{3}$ crystals, the transformation of $\left[\mathrm{SbI}_{3}\right]$ structural units to $[\mathrm{SbSI}]$ with increased heating time further implied the precipitation of AgI microcrystals.

The Nyquist plots of impedance obtained at $25{ }^{\circ} \mathrm{C}$ for the glass-ceramics crystallized at $195{ }^{\circ} \mathrm{C}$ for different durations are shown in Figure 6. In the spectra, Zre' and -Zim” are the real and imaginary components of the impedance $Z(\omega)$, respectively. The sample resistance was determined from the best fit of the semicircular arcs by using an equivalent model consisting of two parallel RQ circuits (where $\mathrm{R}$ is a resistance and $\mathrm{Q}$ is a constant phase element) in series ${ }^{24}$. The intercept point of linear tail in low frequency range with real axis nearly corresponds to the total (bulk and grain-boundary) resistance $Z_{0}$. All the glass-ceramics This article is protected by copyright. All rights reserved. 
had much lower $Z_{0}$ than the base glass. The ionic conductivity (б) calculated from total resistance was $1.49 \times 10^{-4} \mathrm{~S} / \mathrm{cm}$ for the base glass. The $\mathrm{Ag}^{+}$ionic conductivity of glass-ceramics increased at the initial crystallization time from $4 \mathrm{~h}\left(4.68 \times 10^{-4} \mathrm{~S} / \mathrm{cm}\right)$ to $8 \mathrm{~h}$ $\left(4.91 \times 10^{-4} \mathrm{~S} / \mathrm{cm}\right)$, reached a maximum at $12 \mathrm{~h}$ heat treatment $\left(5.68 \times 10^{-4} \mathrm{~S} / \mathrm{cm}\right)$, and decreased after $20 \mathrm{~h}$ heat treatment $\left(4.97 \times 10^{-4} \mathrm{~S} / \mathrm{cm}\right)$. According to the research of Ong $\mathrm{SP}^{25}$, oxygen-substituted compound has much lower ionic conductivity than sulfides compound, because the much smaller anion radius and polarizability of the oxide anion compared to the sulfide anion leading to the lower diffusivity (two orders of magnitude). Thus, combined with the above results, the increased oxygen content of glass-ceramic in this research is not the key for the higher conductivity of glass-ceramics. The relationship between the ionic conductivity of the sample and heat-treatment time can be explained as follows: First, the grain boundary resistance may be reduced by heat treatment because grain boundary resistance is inversely proportional to ionic condcutivity ${ }^{26}$. Second, increase in the amount of precipitated AgI crystals, especially the superionic conductor $\alpha$-AgI phase, partly improves ionic conductivity at prolonged heat treatment time. In fact, the formed structure of SbSI units in a network can present a ribbon framework and forms an effective ionic transport channel for $\mathrm{Ag}^{+}$ions benefiting for the raise of the ionic conductivity ${ }^{7}$. Similar structure units were constructed in the present work, as indicated by the Raman results, for the transport of the $\mathrm{Ag}^{+}$ions. At $20 \mathrm{~h}$ heat treatment, the resultant ionic conductivity decreased as calculated. According to the XRD and Raman results, $\alpha-\mathrm{AgI}$ phase was partially crystallized, and the precipitates were mainly $\beta$-AgI and $\gamma$-AgI crystalline phases. The poorly conducting crystalline ${ }^{27,28}(\beta-\mathrm{AgI}$ and $\gamma-\mathrm{AgI})$ grew and increased continuously, leading to a large crystallinity degree, as shown in This article is protected by copyright. All rights reserved. 
Figure 3(d). Consequently, the precipitated AgI crystalline decreased the amounts of $\mathrm{Ag}^{+}$ transported across the SbSI channel. The drop in $\mathrm{Ag}^{+}$ionic conductivity was caused by disrupted movement of $\mathrm{Ag}^{+}$ions when $\beta-/ \gamma$ - $\mathrm{AgI}$ crystals increased. These results showed the crucial role of controlled microcrystal growth to the transport of conductive ions. The growing of superionic conductor and large amounts of stable $\alpha-\mathrm{AgI}$ in chalcogenide glass is still a continuous hard work for a higher ionic conductivity, leading to the practical value of amorphous solid electrolytes applications.

\section{4 | CONCLUSIONS}

A series of AgI-rich $40\left(0.8 \mathrm{Sb}_{2} \mathrm{~S}_{3}-0.2 \mathrm{Ga}_{2} \mathrm{~S}_{3}\right)-60 \mathrm{AgI}$ electroconductive chalcogenide glass and glass-ceramics were prepared and investigated. The obtained glass-ceramics were highly transparent in the mid-IR region $(2-14 \mu \mathrm{m})$. The XRD results indicated that the precipitated crystalline phase was mainly $\beta / \gamma-\mathrm{AgI}$, and a small amount of $\alpha-\mathrm{AgI}$ was detected in AgI-rich chalcogenide glass-ceramics at room temperature. After the precipitation of AgI, the $\left[\mathrm{SbI}_{3}\right]$ units decomposed and the $[\mathrm{SbSI}]\left[\mathrm{SbS}_{3}\right]$, and $\left[\mathrm{GaS}_{3}-\mathrm{S}_{3} \mathrm{Ga}\right]$ units formed to compensate the loss of $\mathrm{I}^{-}$. The progressive modification of the glass network enhanced the ionic conductivity of the glass-ceramics. The novel AgI-based chalcogenide glass-ceramics is potential for infrared optics and solid electrolyte applications.

This article is protected by copyright. All rights reserved. 


\section{Acknowledgement}

This work was supported by the Natural National Science Foundation of China (NSFC)

(Grant no. 61605093, 51702172 and 61675105), National Key Research and Development Program of China (No. 2016YFB0303802 and 2016YFB0303803), The Open Foundation of State Key Laboratory of Infrared Physics (Grant no. M201510), and sponsored by K. C. Wong Magna Fund in Ningbo University.

\section{References}

1. Ying L, Lin C, Xu Y, Nie Q, Chen F, Dai S. Glass formation and properties of novel $\mathrm{GeS}_{2}-\mathrm{Sb}_{2} \mathrm{~S}_{3}-\mathrm{In}_{2} \mathrm{~S}_{3}$ chalcogenide glasses. Opt Mater. 2011;33:1775-1780.

2. Choi JW, Han Z, Sohn BU, Chen GF, Smith C, Kimerling LC, et al. Nonlinear characterization of GeSbS chalcogenide glass waveguides. Sci Rep. 2016;6:39234.

3. Petersen CR, Møller U, Kubat I, Zhou B, Dupont S, Ramsay J, et al. Mid-infrared supercontinuum covering the $1.4-13.3 \mu \mathrm{m}$ molecular fingerprint region using ultra-high NA chalcogenide step-index fibre. Nat Photonics. 2014;8:830-834.

4. Du Q, Huang Y, Li J, Kita D, Michon J, Lin H, et al. Low-loss photonic device in Ge-Sb-S chalcogenide glass. Opt Lett. 2016;41:3090-3093.

5. Ren J, Yang G, Zeng H, Zhang X, Yang Y, Chen G. Properties of Dy ${ }^{3+}$-doped Ge-As-Ga-Se chalcogenide glasses. J Am Ceram Soc. 2006;89:2486-2491.

6. Zhang X, Calvez L, Seznec V, Ma H, Danto S, Houizot P, et al. Infrared transmitting glasses and glass-ceramics. J Non-Cryst Solids. 2006;352:2411-2415.

7. Lin C, Zhu E, Wang J, Zhao X, Chen F, Dai S. Fast Ag-ion-conducting $\mathrm{GeS}_{2}-\mathrm{Sb}_{2} \mathrm{~S}_{3}-\mathrm{AgI}$

This article is protected by copyright. All rights reserved. 
glassy electrolytes with exceptionally low activation energy. J Phys Chem C. 2018;122:1486-1491.

8. Cui S, Le Coq D, Boussard-Plédel C, Bureau B. Electrical and optical investigations in Te-Ge-Ag and Te-Ge-AgI chalcogenide glasses. J Alloy Compd. 2015;639:173-179.

9. Tang G, Liu C, Luo L, Chen W. Thermal properties, microstructure, and conductivity of new glasses based on the $\mathrm{GeSe}_{2}-\mathrm{Ga}_{2} \mathrm{Se}_{3}-\mathrm{AgI}$ system. $\mathrm{J}$ Am Ceram Soc. 2008;91:4171-4174.

10. Xu B, Wang X. Thermally stable AgI quantum-dot-based room-temperature fast ionic conductors. Small. 2011;7:3439-3444.

11. Tatsumisago M, Shinkuma Y, Minami T. Stabilization of superionic $\alpha-A g I$ at room temperature in a glass matrix. Nature. 1991;354:217-128.

12. Taniguchi A, Tatsumisago M, Minami T. Crystallization kinetics of a-Agl in Agl- based silver orthoborate glasses. J Am Ceram Soc. 1995;78:460-464.

13. Mroczkowska M, Czeppe T, Nowinski JL, Garbarczyk JE, Wasiucionek M. DSC and XRD studies on crystallization kinetics in AgI-rich glassy and glass-crystalline ionic conductors of the AgI- $\mathrm{Ag}_{2} \mathrm{O}-\mathrm{P}_{2} \mathrm{O}_{5}$ system. Solid State Ionics. 2008;179:202-205.

14. Marple M, Kaseman DC, Kim S, Sen S. Superionic conduction of silver in homogeneous chalcogenide glasses. J Mater Chem A. 2016;4:861-868.

15. Huang X, Jiao Q, Lin C, Ma H, Zhang X, Zhu E, et al. Formation, microstructure, and conductivity of a novel $\mathrm{Ga}_{2} \mathrm{~S}_{3}-\mathrm{Sb}_{2} \mathrm{~S}_{3}$-AgI chalcogenide system. Sci Rep. 2018;8:1699.

16. Lin C, Calvez L, Ying L, Chen F, Song B, Shen X, et al. External influence on third-order optical nonlinearity of transparent chalcogenide glass-ceramics. Applied

This article is protected by copyright. All rights reserved. 
Physics A. 2011;104:615-620.

17. Lin C, Calvez L, Bureau B, Tao H, Allix M, Hao Z, et al. Second-order optical nonlinearity and ionic conductivity of nanocrystalline $\mathrm{GeS}_{2}-\mathrm{Ga}_{2} \mathrm{~S}_{3}$-LiI glass-ceramics with improved thermo-mechanical properties. Physical chemistry chemical physics : PCCP. 2010;12:3780-3787.

18. Lin C, Calvez L, Li Z, Dai S, Tao H, Ma H, et al. Enhanced up-conversion luminescence in $\mathrm{Er}^{3+}$-doped $25 \mathrm{GeS}_{2} \cdot 35 \mathrm{Ga}_{2} \mathrm{~S}_{3} \cdot 40 \mathrm{CsCl}$ chalcogenide glass-ceramics. J Am Ceram Soc. 2013;96:816-819.

19. Perry $\mathrm{CH}$, Agrawal DK. The raman spectrum of ferroelectric SbSI. Solid State Communications. 1970;8:225-230.

20. Yang A, Zhang M, Li L, Wang Y, Zhang B, Yang Z, et al. Ga-Sb-S chalcogenide glasses for mid-infrared applications. J Am Ceram Soc. 2016;99:12-15.

21. Li G, Li L, Huang X, Tang J, Dai S, Wang G, et al. $\mathrm{Er}^{3+}$ doped and $\mathrm{Er}^{3+} / \mathrm{Pr}^{3+}$ co-doped gallium-antimony-sulphur chalcogenide glasses for infrared applications. Opt Mater Express 2016;6:3849.

22. Bottger GL, Damsgard CV. Raman scattering in wurtzite-type AgI crystals. J Chem Phys. $1972 ; 57: 1215-1218$

23. Dong G, Tao H, Xiao X, Lin C, Zhao X, Mao S. Mechanism of electron beam poled SHG in $0.95 \mathrm{GeS}_{2} \cdot 0.05 \mathrm{In}_{2} \mathrm{~S}_{3}$ chalcogenide glasses. $\mathrm{J}$ Phys Chem Solids. 2007;68:158-161.

24. Kim SK, Mao A, Sen S, Kim S. Fast Na-ion conduction in a chalcogenide glass-ceramic in the ternary system $\mathrm{Na}_{2} \mathrm{Se}-\mathrm{Ga}_{2} \mathrm{Se}_{3}-\mathrm{GeSe}_{2}$. Chem Mater. 2014;26:5695-5699.

This article is protected by copyright. All rights reserved. 
25. Ong SP, Mo Y, Richards WD, Miara L, Lee HS, Ceder G. Phase stability, electrochemical stability and ionic conductivity of the $\mathrm{Li}_{10 \pm 1} \mathrm{MP}_{2} \mathrm{X}_{12}(\mathrm{M}=\mathrm{Ge}, \mathrm{Si}, \mathrm{Sn}, \mathrm{Al}$ or $\mathrm{P}$, and $\mathrm{X}=\mathrm{O}, \mathrm{S}$ or $\mathrm{Se}$ ) family of superionic conductors. Energy Environ. Sci. 2013; 6:148-156.

26. Ni Y, Zheng R, Tan X, Yue W, Lv P, Yang J, et al. A fluorophosphate glass-ceramic electrolyte with superior ionic conductivity and stability for Na-ion batteries. J Mater Chem A. 2015;3:17558-17562.

27. Wang Y, Huang L, He H, Li M. Ionic conductivity of nano-scale $\gamma$-AgI. Physica B: Condensed Matter. 2003;325:357-361.

28. Cava RJ, Rietman EA. Ionic conductivity of $\beta$-AgI. Phys Rev B. 1984;30:6896-6902.

\section{Figure Captions}

Figure 1. DSC curve for bulk glass of $40\left(0.8 \mathrm{Sb}_{2} \mathrm{~S}_{3}-0.2 \mathrm{Ga}_{2} \mathrm{~S}_{3}\right)-60 \mathrm{AgI}$ at a heating rate of $10{ }^{\circ} \mathrm{C} / \mathrm{min}$

Figure 2. Transmission curves of (a) Vis-NIR and (b) IR spectra for base glass and the corresponding samples crystallized at $195{ }^{\circ} \mathrm{C}$ for $4,8,12$ and $20 \mathrm{~h}$. The inset of (a) shows the photographs of base glass and glass-ceramic under digital microscope $(\lambda=980 \mathrm{~nm})$

Figure 3. SEM micrographs of specimens crystallized at $195{ }^{\circ} \mathrm{C}$ for (a) $0 \mathrm{~h}$, (b) $4 \mathrm{~h}$, (c) $8 \mathrm{~h}$, and (d) $20 \mathrm{~h}$.

Figure 4. XRD patterns of $40\left(0.8 \mathrm{Sb}_{2} \mathrm{~S}_{3}-0.2 \mathrm{Ga}_{2} \mathrm{~S}_{3}\right)-60 \mathrm{AgI}$ base glass and glasses heat-treated at $195{ }^{\circ} \mathrm{C}$ for $4,8,12$, and $20 \mathrm{~h}$. The JCPDF cards 70-1022 ( $\alpha$-AgI), 78-1655 ( $\beta$-AgI), and 9-399 ( $\gamma$-AgI) are also presented.

This article is protected by copyright. All rights reserved. 
Figure 5. Raman spectra of $40\left(0.8 \mathrm{Sb}_{2} \mathrm{~S}_{3}-0.2 \mathrm{Ga}_{2} \mathrm{~S}_{3}\right)-60 \mathrm{AgI}$ base glass and glasses heat-treated at $195{ }^{\circ} \mathrm{C}$ for $4 \mathrm{~h}, 8 \mathrm{~h}, 12 \mathrm{~h}$, and $20 \mathrm{~h}$, respectively, including reference of the $\mathrm{SbSI}$ and $\mathrm{SbI}_{3}$ crystals.

Figure 6. $\mathrm{AC}$ impedance of $40\left(0.8 \mathrm{Sb}_{2} \mathrm{~S}_{3}-0.2 \mathrm{Ga}_{2} \mathrm{~S}_{3}\right)-60 \mathrm{AgI}$ base glass and glasses heat-treated at $195^{\circ} \mathrm{C}$ for $4 \mathrm{~h}, 8 \mathrm{~h}, 12 \mathrm{~h}$ and $20 \mathrm{~h}$, respectively.

\section{Table}

Table 1. Atomic weight percentage of base glass and the precipitated crystalline phase at $195^{\circ} \mathrm{C}$ for $20 \mathrm{~h}$.

\begin{tabular}{ccc}
\hline Element & Atom/\% (Base) & Atom/\% (20 h) \\
\hline $\mathrm{Ga}$ & 5.24 & 4.52 \\
$\mathrm{Sb}$ & 31.38 & 22.18 \\
$\mathrm{~S}$ & 23.00 & 13.86 \\
$\mathrm{Ag}$ & 18.87 & 27.00 \\
$\mathrm{I}$ & 21.19 & 28.45 \\
$\mathrm{O}$ & 0.32 & 3.99 \\
\hline
\end{tabular}

This article is protected by copyright. All rights reserved. 
Table 2. Assignments of Raman shift $\left(\mathrm{cm}^{-1}\right)$ of the $40\left(0.8 \mathrm{Sb}_{2} \mathrm{~S}_{3}-0.2 \mathrm{Ga}_{2} \mathrm{~S}_{3}\right)-60 \mathrm{AgI}$ glass-ceramics.

\begin{tabular}{lll}
\hline Raman shift $\left(\mathbf{c m}^{-\mathbf{1}}\right)$ & Assignments & Refs. \\
\hline 107 & {$[\mathrm{SbSI}]$} & 7,19 \\
138 & {$\left[\mathrm{SbI}_{3}\right]$} & 7 \\
265 & {$\left[\mathrm{GaS}_{3}-\mathrm{S}_{3} \mathrm{Ga}\right]$} & 20 \\
290,314 & {$\left[\mathrm{SbS}_{3}\right]$} & 20,21 \\
\hline
\end{tabular}

This article is protected by copyright. All rights reserved. 


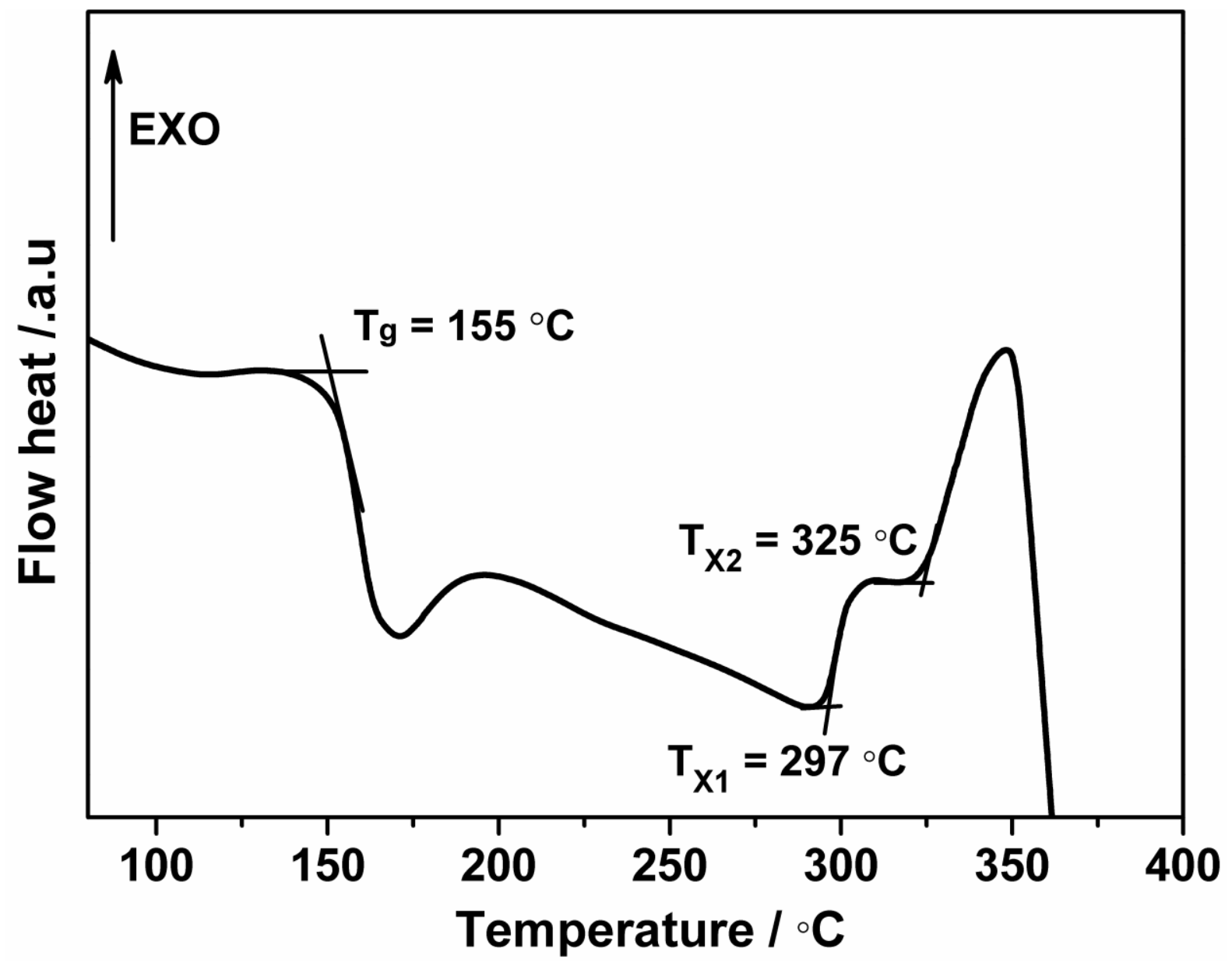

This article is protected by copyright. All rights reserved. 

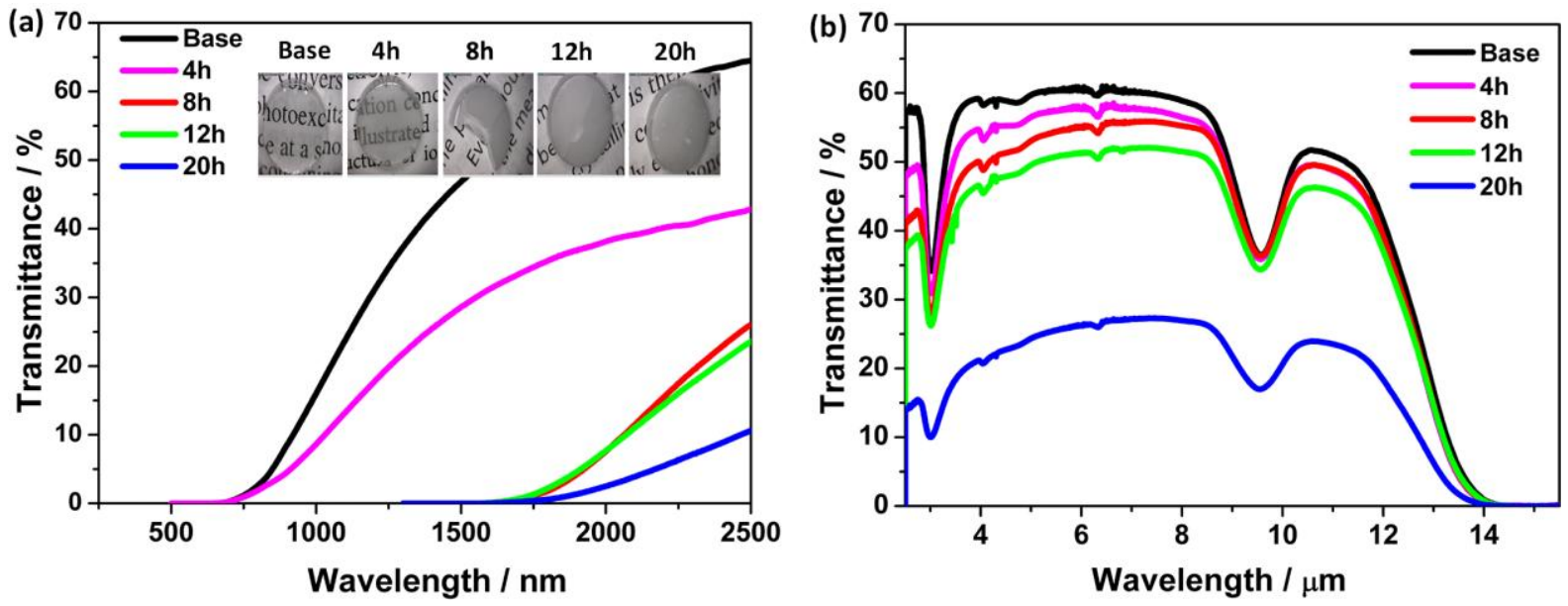

This article is protected by copyright. All rights reserved. 


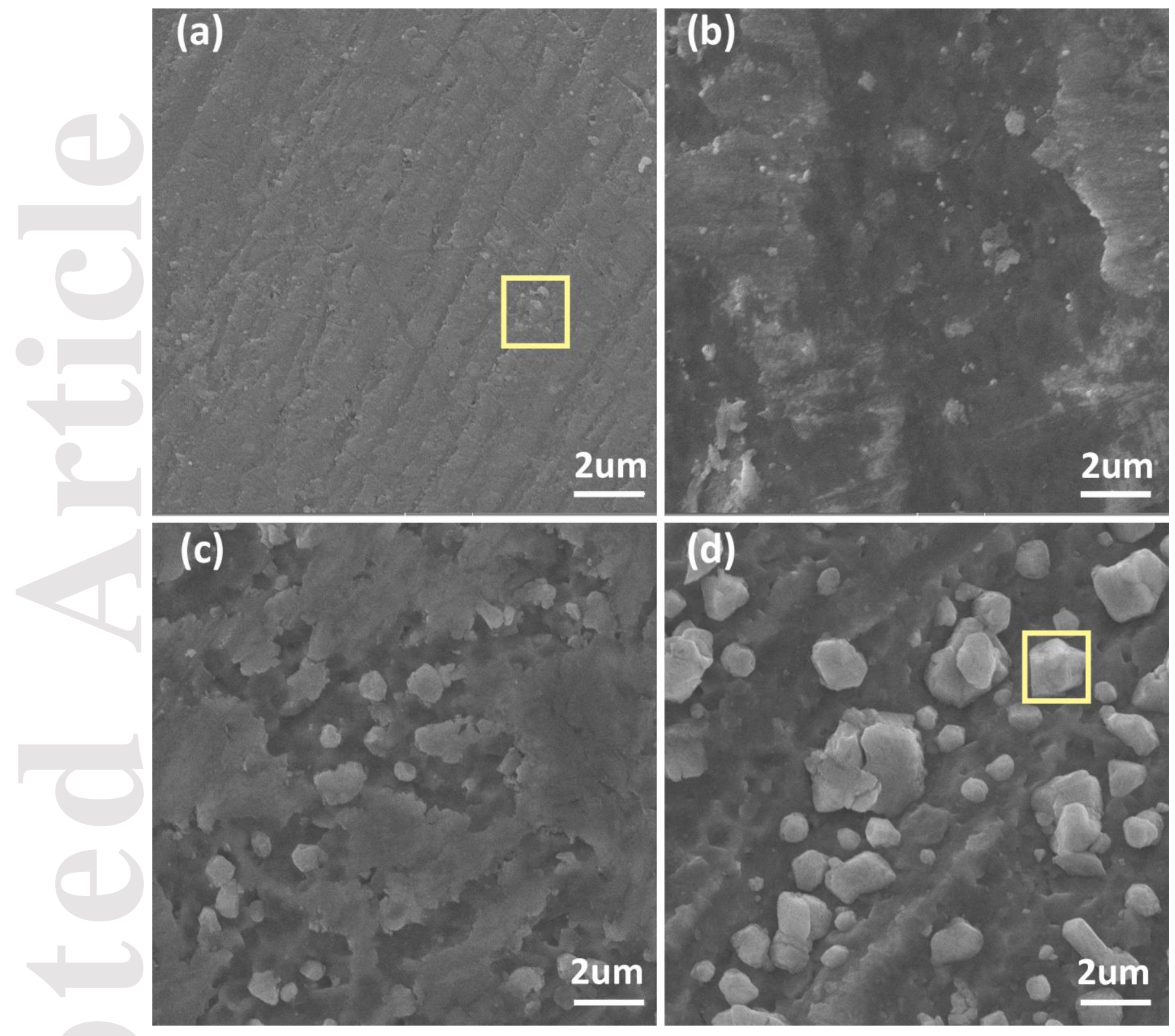

This article is protected by copyright. All rights reserved. 


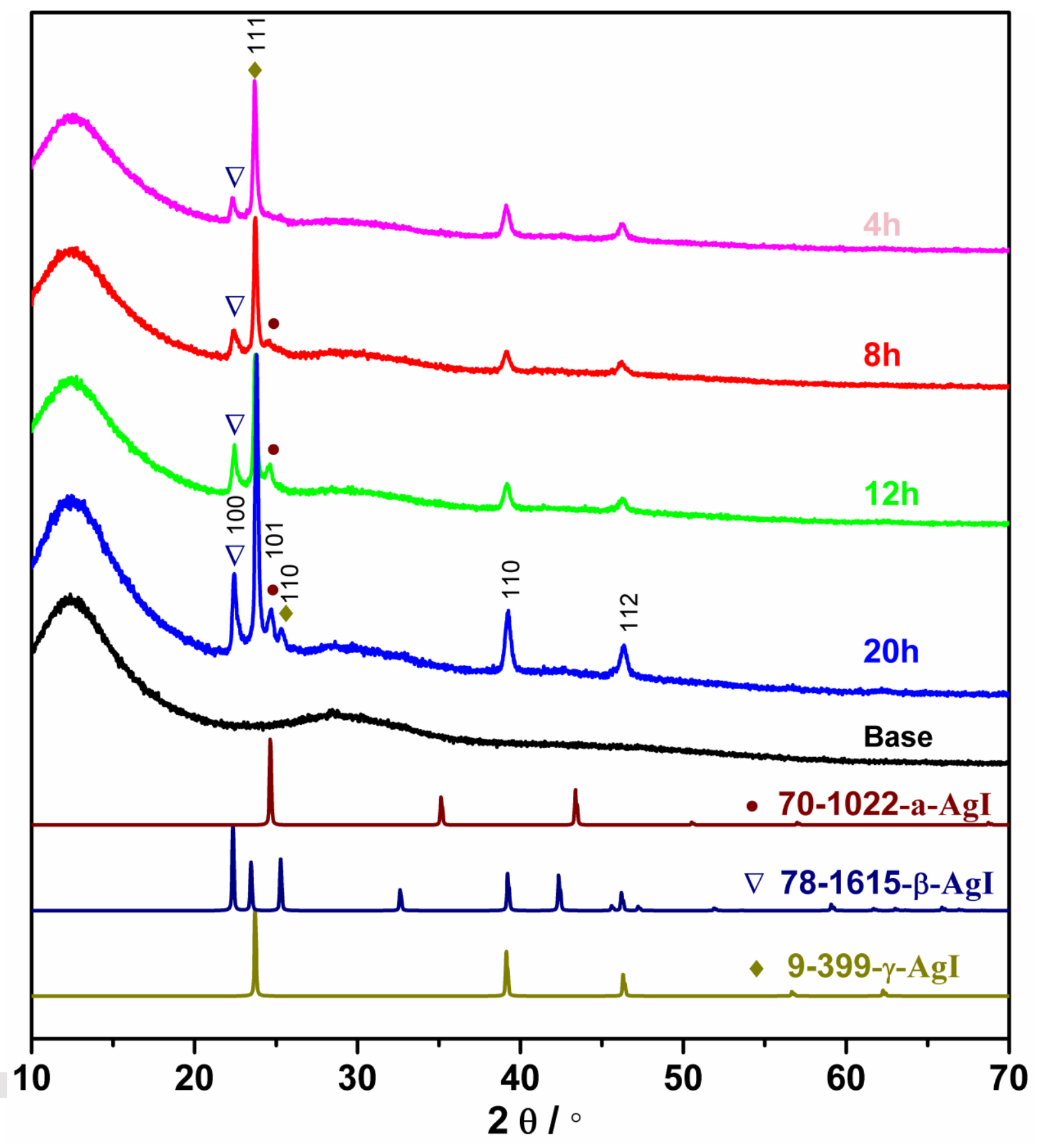

This article is protected by copyright. All rights reserved. 


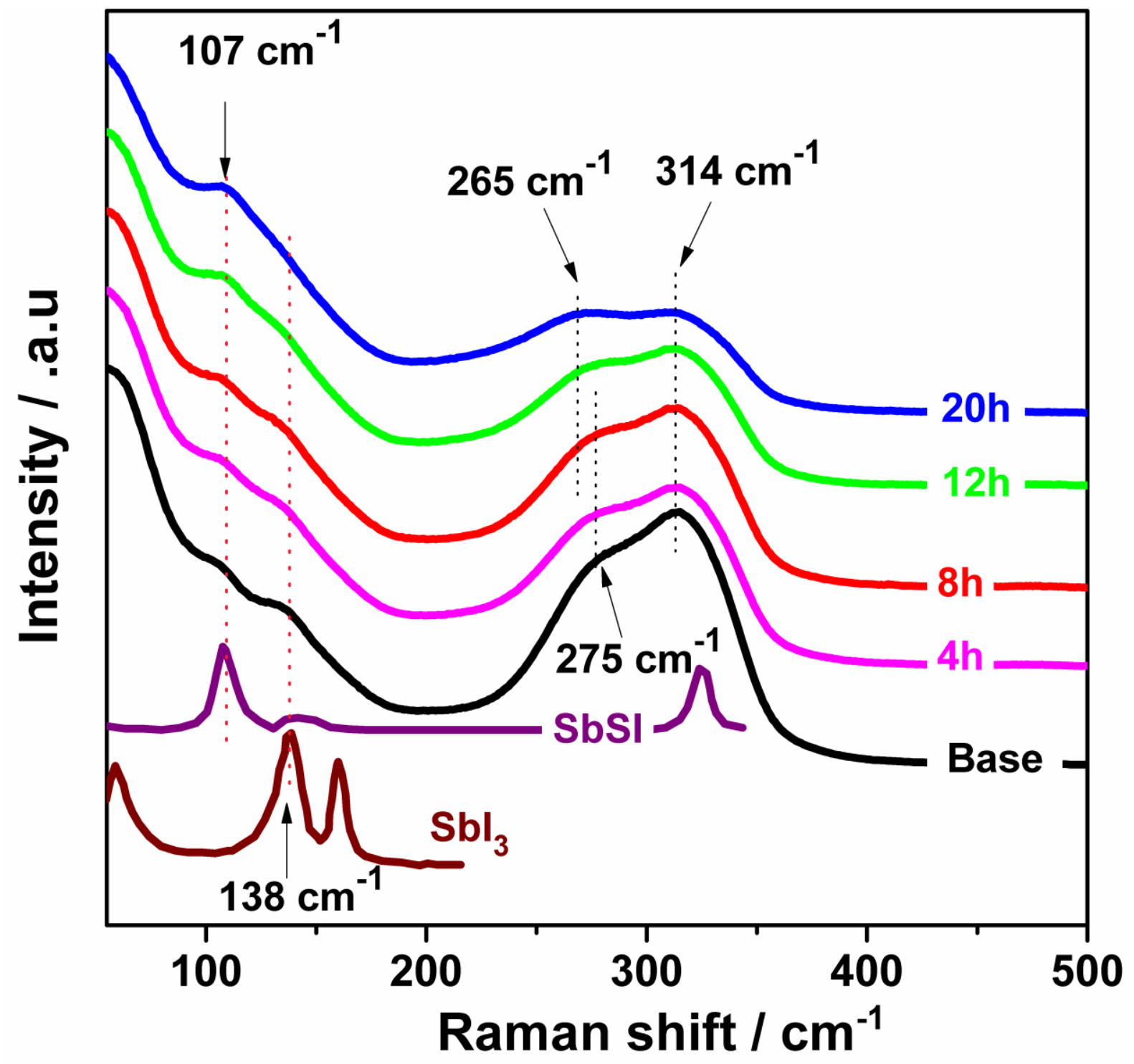

This article is protected by copyright. All rights reserved. 


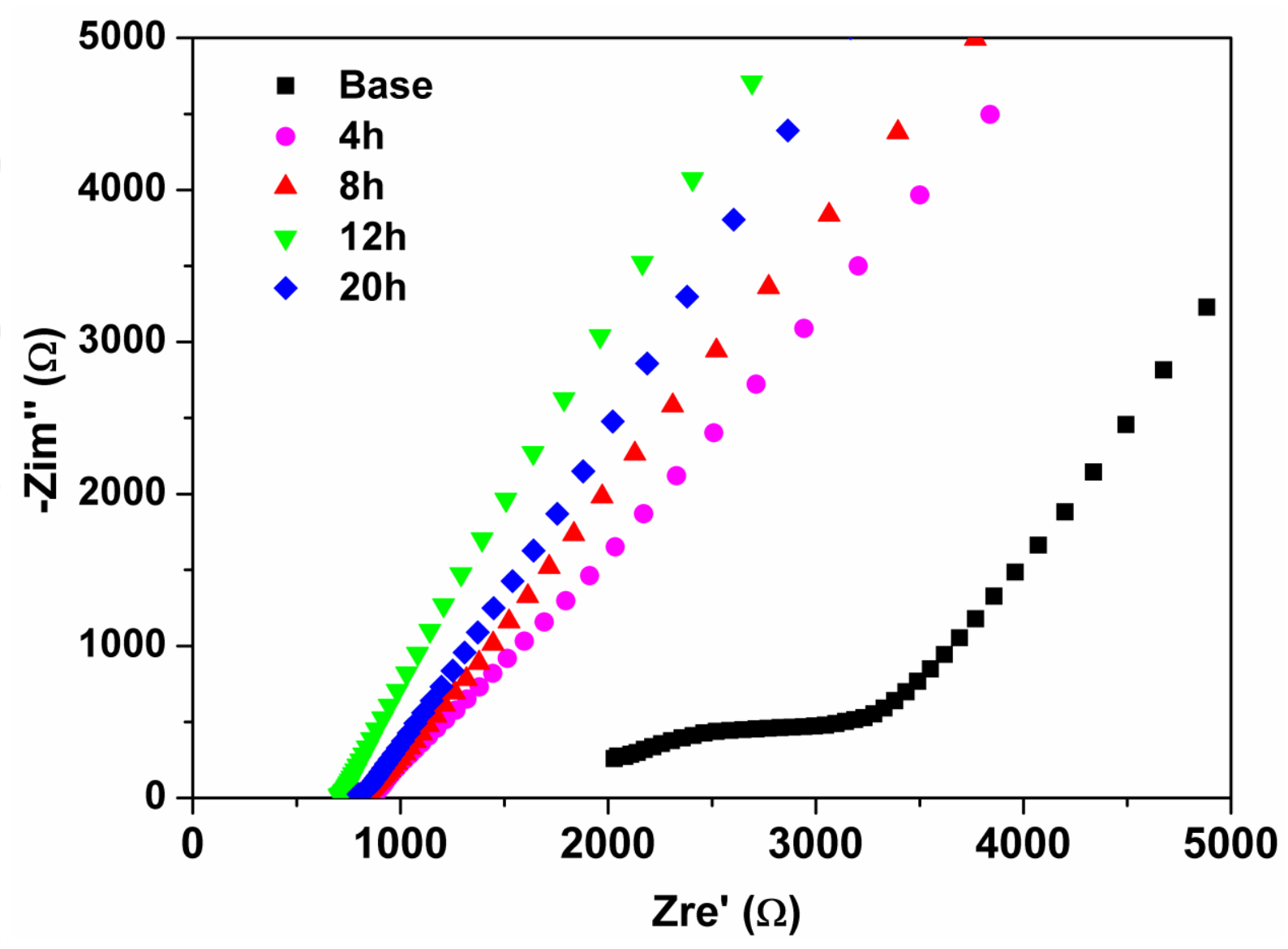

This article is protected by copyright. All rights reserved. 